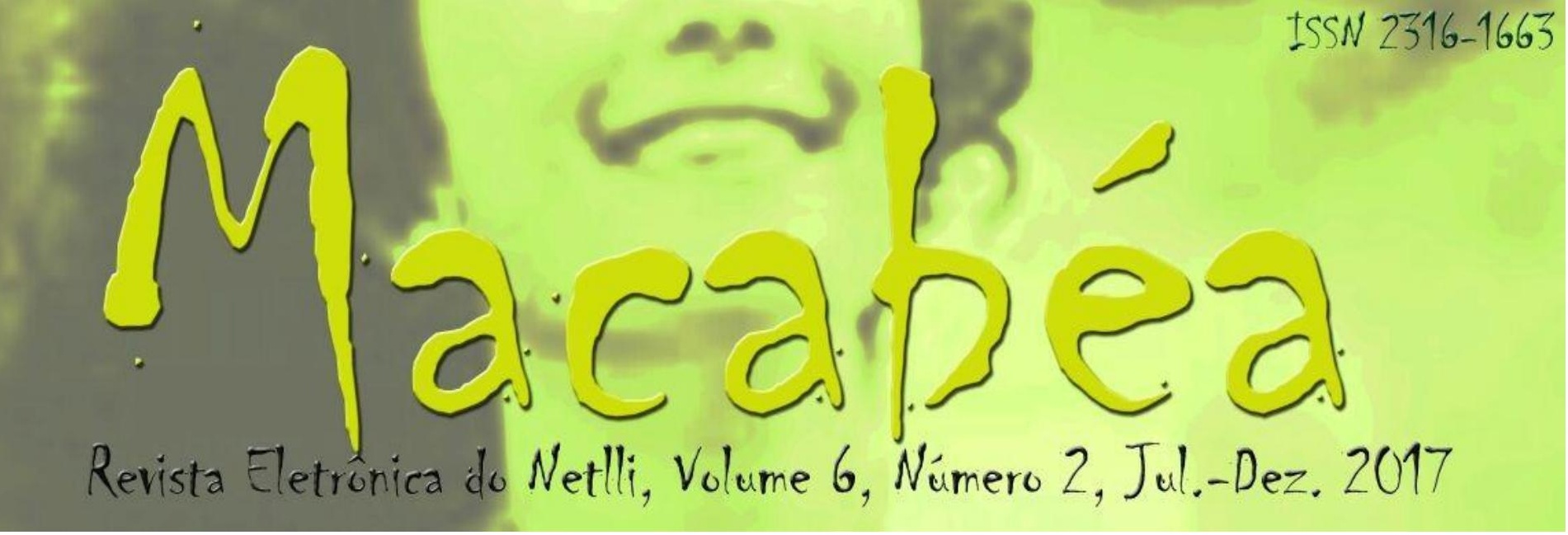

\title{
GRAMÁTICA: GÊNERO DISCURSIVO EM MUTAÇÃO?
}

\section{GRAMMAR: DISCURSIVE GENRE UNDER MUTATION?}

\section{CARDOSO, Maísa ${ }^{1}$ \\ Universidade Federal do Paraná (UFPR)}

RESUMO | INDEXAÇÃO | TEXTO | REFERÊNCIAS | CITAR ESTE ARTIGO | OS AUTORES RECEBIDO EM 06/05/2016 • APROVADO EM 16/01/2018

\section{Abstract}

Current analysis comprises a discussion on normative grammar coupled to several inquiries: a) May this text be considered a discursive genre? b) If grammar is a discursive genre, how are modern grammars published in the 2000s, or the linguists' grammars, to be considered? Are they a transformation of the genre or a new genre? The answer may be provided by Bakhtin $(2002,2004)$ with his theory on discursive genres and plurilinguism, and by Travaglia (1998) and Possenti (1997) for the classification of grammars and in reviews on the grammar under analysis and in their prefaces. Grammar may be considered a discursive genre even though it is a discursive genre which is different from traditional grammar. The new grammars have stable marks of the grammar genre and they may be considered as a genre characterized by plurilinguism. However, they introduce a grammar with a new approach, disrupting the myth of the single idiom. Current investigation comprises discussion on the discursive genre; a classification of grammars; a comparison between Cegalla's traditional grammar Novíssima Gramática da Língua Portuguesa (1978) and Pequena Gramática do Português brasileiro (CASTILHO; ELIAS, 2012), both written for didactic purposes. 
A proposta deste artigo é iniciar uma discussão que envolve a gramática normativa pensando em algumas indagações: a) este texto pode ser considerado um gênero discursivo? Decorrente desta, há outra questão a ser pensada: b) se gramática é gênero discursivo, como observar as modernas gramáticas que foram publicadas nos anos 2000 as gramáticas dos linguístas? Serão uma transformação do gênero ou novo gênero? Para refletir sobre isso, buscamos Bakhtin $(2002,2004)$, em sua teoria de gêneros discursivos e pluringuismo; Travaglia (1998) e Possenti (1997) para classificar as gramáticas e em resenhas feitas sobre a gramática em questão e nos prefácios dessas obras. A conclusão é que é possível pensar a gramática como gênero discursivo; apesar de ser um gênero discursivo diferenciado da gramática tradicional. Inauguram uma gramática que apresenta nova abordagem, rompendo com o mito da língua única. Para apresentar a discussão, seguiremos o trajeto: discussões acerca de gênero discursivo, depois faremos uma breve classificação das gramáticas e por fim, a comparação entre a gramática tradicional do Cegalla, "Novíssima Gramática da Língua Portuguesa" (1978) e a "Pequena Gramática do Português brasileiro" (CASTILHO; ELIAS, 2012) -ambas escritas para fins didáticos

Entradas para indexação

KEYWORDS: Grammars; discursive genres; linguistic policies.

PALAVRAS-CHAVE: Gramáticas; Gêneros discursivos; Políticas Linguísticas

\section{Texto integral}

\section{INTRODUÇÃO}

A gramática normativa é, sem dúvida, um texto que merece olhares científicos. Dentre tantas razões, uma delas é o fato desse texto sobreviver há anos na sociedade, principalmente no contexto escolar, com formatação e objetivo basicamente igual aos das primeiras gramáticas. É extrema a força que este texto mantém na sociedade brasileira, um lugar de supremacia quando se pensa o uso/ensino de língua portuguesa. Por isso, a proposta deste artigo é apresentar uma discussão que envolve a gramática normativa pensando em algumas indagações: a) este texto pode ser considerado um gênero discursivo? Decorrente desta, há outra questão a ser pensada: b) se gramática é gênero discursivo, como observar as modernas gramáticas que foram publicadas nos anos 2000 - as gramáticas dos linguístas? Serão uma transformação do gênero ou novo gênero?

Para refletir sobre isso, buscamos Bakhtin (2002, 2004), em sua teoria de gêneros discursivos e pluringuísmo; Travaglia (1998) e Possenti (1997) para classificar as gramáticas, em resenhas feitas sobre a gramática em questão e nos prefácios dessas obras.

A conclusão é que é possível pensar a gramática como gênero discursivo e, embora apresentem diferenciada concepção de língua e uso de língua, as novas gramáticas mantém marcas estáveis do gênero gramática. Seguiremos o trajeto: discussões 
acerca de gênero discursivo, depois faremos uma breve classificação das gramáticas e por fim, a comparação entre a gramática tradicional do Cegalla, "Novíssima Gramática da Língua Portuguesa" (1978) e a "Pequena Gramática do Português brasileiro" (CASTILHO; ELIAS, 2012) -ambas escritas para fins didáticos

\section{A GRAMÁTICA É UM GÊNERO DISCURSIVO?}

Os estudos sobre gêneros discursivos povoaram as academias e as salas de aula há alguns anos. Suas discussões ficaram mais enfáticas com a publicação dos PCNS nos anos 90, uma vez que a base para o ensino da língua materna destacado no documento oficial é o gênero discursivo. Assim, as falas bakhtinianas nos são conhecidas. A ideia de que nos comunicamos por gêneros discursivos que são relativamente estáveis quanto à estrutura, tema e estilo é teoria conhecida pela maioria das pessoas interessadas nos estudos do texto, discurso e em discussões sobre sala de aula.

Pensando nessa teoria do gênero, temos na escola, na acadêmica e em outros lugares da sociedade, um livro bastante antigo e conhecido: a gramática. Assim, primeiro discutiremos a sua categorização quanto a ser suporte de gênero ou gênero discursivo (gramática obra - livro material- usada desde tempos nas escolas brasileiras). Segundo Marcuschi (2002), em seus estudos iniciais sobre o tema, não é tão simples classificar um suporte de gênero. Os limites entre suporte e gênero são tênues e, por vezes, questionáveis .

No entanto, é inegável a noção de que o suporte é imprescindível para a realização e circulação dos gêneros na sociedade e, de certo modo, podemos afirmar que o suporte exerce alguma influência sobre o gênero suportado (MARCUSCHI, 2008). A razão é que o gênero não é indiferente ao suporte e, em certos casos, é o suporte que determina a distinção que o gênero recebe. Em estudos posteriores, com elaborações de categorização mais clara quanto à suporte, o autor declara que o suporte é identificado por três aspectos: a) suporte é um lugar (físico ou virtual): ele deve ser algo real, ainda que essa realidade seja virtual, como é o caso do suporte representado pela internet. No entanto, essa materialidade do suporte é essencial e imprescindível; b) suporte tem formato específico: embora os suportes não sejam uniformes, cada um deles apresenta uma forma precisa; c) suporte serve para fixar e mostrar o texto: a função principal do suporte é fixar o texto e possibilitar o seu acesso para fins comunicativos.

Marcuschi (2008), em seus estudos, ainda classifica dois tipos de suportes: suportes que foram criados para serem portadores de textos, aos quais denomina suportes convencionais. E suportes incidentais, que operam como ocasionais ou eventuais, ou seja, podem trazer textos, mas não foram necessariamente criados para esse fim e nem operam na atividade comunicativa regular. Apesar de o autor lembrar que não se trata de uma classificação fechada e exaustiva, intitula como convencionais os seguintes suportes: folha de papel, livro, jornal (diário), revista (semanal/mensal), revista científica (boletins e anais), rádio, televisão, telefone, quadro de avisos, outdoor, encarte, folder, luminosos e faixas. 
Notamos que nesta lista de suportes convencionais está o livro. Sendo assim, considerada por muitos que a gramática é um suporte textual para vários gêneros discursivos que a compõem como exercícios, regras, definições etc.

Porém, ao observarmos a reflexão de Marcuschi (2008) sobre suporte, retomamos sua própria afirmação de que não é tão simples assim. Por exemplo, o autor cita o livro como suporte convencional, pois ele comportaria uma gama de gêneros discursivos, é o caso de um livro (suporte de gênero) de crônicas (gênero discursivo) - uma coletânea. No entanto, na continuação da discussão, cita o gênero Tese (Tese de doutorado) e faz um comentário- sobre ser gênero ou ser suporte (MARCUSCHI, 2003, p.19 - em nota):

Não é meu interesse discutir aqui aspecto delicado a respeito dos gêneros que compõem a tese de doutorado, pois é sabido que numa tese de doutorado (e em vários outros gêneros) temos pelo menos os seguintes gêneros que compõem aquele gênero: resumo; sumário; índices remissivos; agradecimentos; prefácio; introdução; bibliografia. Estes gêneros têm funções e estrutura próprias, mas quando reunidos numa dada sequência para constituir uma tese de doutorado, eles não são mais vistos como gêneros e sim como transmutados para compor as partes de uma tese. Este aspecto mereceria mais atenção até para se perceber como os gêneros derivam um do outro e muitas vezes são composições complexas como bem lembrava Bakhtin [1979].

Neste caso, acreditamos que a Tese é um gênero discursivo e não necessariamente um suporte textual. Vejamos a questão do gênero para procurarmos demonstrar nossa contrariedade quanto a essa classificação e assim, quem sabe, pensar a classificação da gramática como gênero e não como suporte.

Ancorados em Bakhtin (2004 ), entendemos que o emprego da língua efetua-se em forma de enunciados (orais e escritos) concretos e únicos, proferidos pelos integrantes desse ou daquele campo de atividade humana. Apresentam traços em comum enquanto unidades de comunicação e podem variar em termos de extensão, conteúdo e estrutura. Também refletem as condições específicas e as finalidades de cada texto não só por seu conteúdo (temático) e pelo estilo da linguagem (seleção dos recursos lexicais, fraseológicos e gramaticais da língua), mas, acima de tudo, por sua construção composicional (BAKHTIN/ VOLOCHINOV, 2004). Bakhtin faz ainda uma classificação entre gênero primários e secundários:

Aqui é de especial importância atentar para a diferença essencial entre os gêneros discursivos primários (simples) e secundários (complexosromances, dramas, pesquisas cientificas de toda espécie, os grandes gêneros publicísticos, etc.) surgem nas condições de um convívio cultural mais complexo e relativamente muito desenvolvido e organizado (predominantemente o escrito) - artístico, cientifico, sociopolítico, etc. No processo de na sua formação eles incorporam e reelaboram diversos gêneros primários (simples), que se formaram nas 
condições da comunicação discursiva imediata. Esses gêneros primários que integram os complexos, aí se transformam e adquirem um caráter especial: perdem o vínculo imediato com a realidade concreta e os enunciados reais alheios (...)(p. 263)

Schneuwly (2004), explicando Bakhtin, declara que os gêneros secundários não são espontâneos e sua apropriação implica outro tipo de intervenção nos processos de desenvolvimento, diferente do necessário para o desenvolvimento dos primários. Eles introduzem uma ruptura, pelo fato de não estarem mais ligados de maneira imediata a uma situação de comunicação. Como não emergem de esferas já conhecidas pelo aprendiz, de suas experiências pessoais, mas de situações mais complexas (SCHNEUWLY, 2004, p.33), a apropriação dos gêneros secundários não pode ser feita diretamente pelo aprendiz, que é confrontado com estes numa situação não necessariamente ligada ao contexto preciso imediato. É o caso da gramática que emerge de contextos escolar/acadêmico, lugares de estudo da língua. Se tomarmos dessas definições bakhtinianas e procurarmos aplicar à gramática, teremos assim sua caracterização:

- $\quad$ Texto que se encontra em nossa vida diária - escola e ambientes sociais que requerem estudo e uso da oralidade formal e escrita (com ênfase na norma culta);

- $\quad$ Texto com padrões sócio -comunicativos definidos por composição - as gramáticas são bastante padronizadas - basta olhar em seus sumários/índices, seleção de conteúdos e organização dos formatos de apresentação do conteúdo;

- $\quad$ A gramática - sendo gênero - é definida por objetivos enunciativos bem marcados - preescrever - instruir quanto à escrita/oralidade ;

- $\quad 0$ estilo da gramática é marcado por forças históricas - as gramáticas mantém padrões de estilo tão antigos quanto o gênero; frases injuntivas, definições, explicações e regras, predomínio de terceira pessoa... - $\quad$ A gramática é uma entidade empírica e tem designação clara qualquer pessoa que ouça a palavra gramática se referindo a livro sabe que se trata de um texto que visa instruir quanto ao bom uso da linguagem culta;

- $\quad$ Consequentemente, é uma forma textual escrita relativamente estável, histórica e socialmente marcada.

Se ela não é suporte, é um gênero discursivo, como explicar os textos que a compõem? Consideraremos a gramática um gênero secundário e complexo, uma vez que este gênero comporta em si outros gêneros que a compõem - como o exemplo de Marcuschi (2003) -, assim acreditamos ser a Tese. Recorremos a Bakhtin (2002) que, ao tratar sobre o gênero romance, sinaliza um plurilinguismo para além do estilo lingüístico, o que diz respeito aos gêneros intercalados:

é graças a este plurilinguismo social e ao crescimento em seu solo de vozes diferentes que o romance orquestra todos os seus temas, todo seu mundo objetal, semântico, figurativo e expressivo. 0 discurso do autor, os discursos dos narradores, 
os gêneros intercalados, os discursos das personagens (2002, p. 74)

e

Finalmente, deter-nos-emos ainda sobre uma das formas mais importantes e substanciais de introdução e organização do plurilinguismo no romance: os gêneros intercalados (...)

0 romance admite introduzir na sua composição diferentes gêneros, tanto literários (novelas intercaladas, peças líricas, poemas, sainetes dramáticos, etc.), como extraliterários (de costumes, retóricos, científicos, religiosos e outros). Em princípio, qualquer gênero pode ser introduzido na estrutura do romance, e de fato é muito difícil encontrar um gênero que não tenha sido alguma vez incluído num romance por algum autor. Os gêneros introduzidos no romance conservam habitualmente a sua elasticidade estrutural, a sua autonomia e a sua originalidade lingüística e estilística. Porém, existe um grupo especial de gêneros que exercem um papel estrutural muito importante nos romances, e às vezes chegam a determinar a estrutura do conjunto(...). São eles: a confissão, o diário, o relato de viagens, a biografia, as cartas e alguns outros gêneros. Todos eles podem não só entrar no romance como seu elemento estrutural básico, mas também determinar a forma do romance como um todo (romance confissão, romancediário, etc.). (2002, p. 124)

Essas discussões de Bakhtin (2002) auxiliam-nos a pensar que o gênero discursivo gramática é marcado por este plurilinguismo e outros gêneros são seus constituintes.

\section{A GRAMÁTICA TRADICIONAL E AS NOVAS GRAMÁTICAS}

Em seu texto Português na escola- história de uma disciplina curricular (2002, p.155), Magda Soares (ao pensar a história da disciplina de Português), observa que, desde o século XVI até metade do século XVIII, a gramática despontou como disciplina fundamental. Em princípio, estudávamos a gramática da língua latina nas escolas brasileiras e apenas por volta de 1776 - a gramática da Língua Portuguesa passou a fazer parte do currículo por obrigatoriedade da Reforma Pombalina.

Além disso, em função do latim perder seu valor social, gramáticas brasileiras - agora como obras impressas, compêndios - foram surgindo em 1808 - 
normalmente, escritas por professores para alunos; assim, observa-se que os estudos da gramáticas uma tradição que remonta anos e anos. Assinalamos nessas produções de gramática, bem como em seu ensino, uma política linguística, no Brasil, cuja concepção de língua é única como norma a ser seguida e respeitada (SOARES, 2002)|. Desse modo, na segunda metade do século XIX, não só seu ensino como também os compêndios chamados gramática, ganharam maior presença e prestígio nas salas de aulas brasileiras. Júlio Ribeiro, professor de retórica do Colégio Pedro II, no Rio de Janeiro, foi um dos principais autores de gramáticas, legitimando cada dia mais uma posição de autoria - o gramático - desses manuais que se estende quase incólumes ao longo de todos os anos até os tempos atuais. Sua "Gramática Portuguesa" esteve presente nas salas de aula do ensino médio até o final das décadas do século XIX . Outro autor que comprova a tradição da gramática é João Ribeiro que, em 1881, publicou sua obra que chegou a 97ª edição para curso elementar.

Desse modo, ao tratarmos da gramática até aqui estamos assinalando um gênero discursivo presente, por muitos anos nas salas de aula. Exerceu, durante o século XX, a função de dizer o que era e o que não era permitido dizer quanto à língua do país e como deveria ser estudada e ensinada (FARIAS, 2014). Com a chegada das teorias linguísticas modernas, a gramática tradicional passou a ser questionada e deixou de ser única referência para representação da língua. Porém só academicamente essas outras teorias alcançaram prestígio, socialmente, a gramática ainda detém o poder quanto ao estudo da língua.

Apesar do poder que exercem de longa data na normatização da língua, observamos que este manual de boas maneiras, nos últimos anos, está disputando espaço com outras gramáticas, chamadas "gramáticas dos linguístas". A primeira delas foi a "Gramática de usos do português" (NEVES, 2000), logo em seguida, registramos, em ordem cronológica, as seguintes publicações: "Gramática Houaiss da língua portuguesa" (AZEREDO, 2008), "Gramática do brasileiro" (FERRAREZI JR.; TELES, 2008), "Gramática do português brasileiro" (PERINI, 2010), "Nova gramática do português brasileiro" (CASTILHO, 2010), "Gramática pedagógica do português brasileiro" (BAGNO, 2011), "Pequena gramática do português brasileiro" (CASTILHO; ELIAS, 2012) e "Gramática de bolso do português brasileiro" (BAGNO, 2013).

Seriam essas gramáticas iguais ao mesmo gênero "gramática" com que estávamos habituados? Teriam os mesmos objetivos? Estão direcionadas aos mesmos interlocutores? Para pensarmos essas indagações, na continuação, fizemos uma análise comparativa entre duas gramáticas dos dois tipos, uma gramática normativa de Cegalla, modelo tradicional e uma nova gramática de Castilho e Elias (2012) a fim de traçarmos algumas semelhanças e diferenças entre esses dois tipos de gramáticas. Antes, porém, faremos uma apresentação dos estudos de Travaglia (1998) e Possenti (1997) quanto a tipos de gramáticas existentes.

\subsection{TIPOS DE GRAMÁTICA}

A gramática tradicional que escolhemos como exemplo - Cegala(1978) - é 
uma gramática muito utilizada em sala de aula e tão bem conhecida por todos que, por vezes, temos a impressão que não há outros tipos de gramáticas. Alguns estudiosos como Possenti (1997) Travaglia (1998) discorrem sobre isso e, diferente do senso comum, atentam para os algumas gramáticas.

Para Travaglia (1998), há conceitos diferentes, tipos e ensino diferentes de gramática. Segundo o autor, a gramática tradicional é concebida como um manual com regras de bom uso da língua a serem seguidas por todos que querem se expressar adequadamente. Rotulada de gramática normativa é um conjunto sistemático de normas para falar e escrever bem, baseado no uso da língua consagrado por bons escritores. A variedade predominante nesta gramática senão única - é a padrão ou culta sendo outras formas de uso consideradas erros, deformações da língua (TRAVAGLIA, 1998, 24). Usando um exemplo de Possenti (1997, p.65), o caso da regra de concordância em que o verbo deve concordar com o sujeito, que existe uma forma única para cada tempo, modo e pessoa do verbo.

Outro conceito é o de gramática descritiva: um conjunto de regras que o cientista encontra nos dados que analisa, com teorias e métodos pré-estabelecidos. Gramática será então tudo o que atende às regras de funcionamento da língua de acordo com uma variedade linguística. Um bom exemplo citado por Possenti (1997, p. 66) é o caso das descrições do português oral dos futuros sintéticos no uso do português brasileiro - os quais são raros, adotando a maioria dos usuários da língua a locução (sairei x vou sair). Neste caso, o cientista pode fazer gramáticas de todas as variedades da língua.

Há ainda o conceito de gramática internalizada que consiste no conjunto de regras que o falante aprendeu e do qual se favorece para falar, sem que dependa de escolarização para seu uso. É a possibilidade que qualquer falante tem de identificar frases como pertencentes à língua e a sua capacidade de produzir sequências sonoras que se caracterizam como pertencentes a determinada língua.

Esses conceitos levam aos tipos de gramática: normativa, descritiva e internalizada (TRAVAGLIA,1998; POSSENTI, 1997). A gramática normativa é a que concebe a gramática como manual de regras para o bem falar, baseando -se nos fatos da língua escrita e descrição da norma ou variedade culta da língua. Como uma lei, a gramática normativa funciona quando, além de só descrever os fatos da norma culta, ainda considera "erros" qualquer outro uso ou variedade. É a gramática mais presente nas escolas e mais popularmente conhecida. Em Possenti (1997, p.78) observamos que nela encontramos o conceito mais corrente de "erro".

A descritiva descreve e registra uma determinada variedade da língua em um momento de sua existência, sincronicamente (TRAVAGLIA, 1998, p.32). Sendo assim, qualquer variedade linguística pode ser foco de descrição desta gramática. Nesse caso, a preocupação deste gramático é deixar explicitar as regras utilizadas , de fato, pelos falantes. As regras realmente seguidas (POSSENTI, 1997, p. 64). Já a internalizada, é a gramática que concebe os usos já sabidos do falante, internalizados por meio do cotidiano, nas interações sociais da qual faz parte (TRAVAGLIA, 1998, p. 32). 


\section{ANÁLISE COMPARATIVA}

A gramática tradicional, modelo que escolhemos, foi usada durante muito tempo - e até hoje - no contexto escolar para o ensino fundamental II e para o ensino médio. Tratamos de uma gramática normativa, como define o autor no prefácio da obra. Em princípio, analisaremos essa gramática como gênero discursivo, seguindo algumas das categorias bakhtinianas. Como atentamos, em sua definição de gênero, Bakhtin (2004) destaca três constituintes do gênero: tema, estilo e aspecto composicional. 0 tema da gramática, ou seja, do que trata uma gramática? Aspectos gramaticais ou "fatos gramaticais" como chama Cegalla (1978); regras de "bom uso" de uma determinada língua, no caso portuguesa. 0 tema da gramática são fatos gramaticais pertencente à norma culta, variante prestigiada. São regras para o uso da linguagem baseadas no modelo prestigiado de linguagem. Sem dúvida, um gênero da ordem das prescrições, o qual visa apresentar regras, instruções de uso da linguagem. Para tanto, essa versão, apresenta as regras de usos e exemplos com base em textos de autores renomados, "consagrados", os quais escrevem de modo "exemplar" além de exercícios para a prática da teoria.

Cegalla (1978) destaca, no prefácio, que a finalidade desse gênero discursivo é ser "um meio posto a nosso alcance para disciplinar a linguagem e atingir a forma ideal da expressão oral e escrita (xvii)". Nela, há exposição dos fatos gramaticais com exercícios e textos de "conceituados e primorosos escritores brasileiros de nossa época (xvii)". Nesse sentido, assinalamos que a tradicional gramática tem como corpus sempre autores literários, canonizados como donos de uma linguagem "impecável”.

Nesse volume de 1978, observamos que o intuito do manual é "disciplinar a linguagem" a fim de que o leitor/aprendiz possa "atingir a forma ideal da expressão oral e escrita", ainda afirma que se destina aos que "aspiram a falar e escrever com acerto e elegância".

0 estilo é a seleção dos recursos lexicais, fraseológicos e gramaticais da língua manifestados no gênero (BAKHTIN, 2004, p. 279 ); quanto à gramática de Cegalla, podemos observar que os recursos linguísticos usados na gramática são recursos provenientes do repertório lexical da norma culta, como também frases explicativas, declarativas e imperativas em $33^{\text {a }}$ pessoa. 0 interlocutor é apresentado diretamente no prefácio: "mestres e alunos", porém não é citado durante o texto restante, uma vez que o gênero usa linguagem impessoal e só dirige-se ao leitor com indicações nos exercícios, nos usos do imperativo. Exemplos:

16. O verbo concorda com o sujeito, em harmonia com as seguintes regras gerais. [ capítulo sobre concordância verbal, p. 294]

a) o sujeito é simples. 
17. o sujeito sendo simples, com ele concordará o verbo em numero e pessoa:

"As saúvas eram uma praga." (P.C.) [

"Tu não és inimiga dele, não?" (C.C.B)

(...)

[exercícios, 305]

1. Justifique a concordância dos verbos nos exemplos seguintes:

a) "É a mofina a condição dos povos em que faltam lavradores e sobejam legisladores.” (M.M.) (CEGALLA, 1978, p. 294, 305)

Bakhtin (2004) afirma que o estilo pode ser individual, apresentando marcas mais subjetivas de autoria, porém destaca que alguns gêneros estão mais limitados que outros quanto a essa exposição individual do estilo. É o caso de gêneros mais padrões ou oficiais (como atas, contratos, por exemplo e as gramáticas tradicionais). A gramática tradicional pode ser considerada um gênero secundário cujo estilo não favorece uma manifestação individual clara do autor, assim, as frases aparecem em formato de prescrições, regras do falar bem, em norma culta de língua portuguesa. Apresenta, geralmente, como esta gramática do Cegalla, tópicos com explicações da regra e exercícios para aplicação/fixação da regra. 0 manual ausenta-se de qualquer informalidade, pretendendo um estilo de linguagem formal, um certo distanciamento entre aquele que escreve e aquele que aprende, sem propor interações mais enfáticas.

Já a construção composicional, formato ou estrutura de uma gramática tradicional não fogem do modelo escolhido. Encontramos nela alguns gêneros que a compõem: prefácio/apresentação, breve histórico da língua portuguesa, conteúdos de estudos divididos em grandes áreas da língua portuguesa (Fonética, Morfologia, Semântica, Sintaxe e Estilística e outros) e referências, nas mais antigas, ainda contamos com Antologia (é o caso deste exemplar de 1978). Dentro dos capítulos, encontramos divisões de estudos do conteúdo bem padronizadas, num esquema: exemplo do fenômeno da língua + definição do fenômeno + exemplos com citações de autores renomados + exercícios . Há mudanças tênues nessa organização ao longo dos anos, como é o caso da inserção de textos recorrentes em outras esferas de comunicação, além da acadêmica ou literária, como é o caso de exemplos de propagandas, publicidades, trechos de reportagens, notícias e fotografias para exemplificar fatos da língua em detrimento de coletâneas de autores literários. Apesar disso, na maior parte das vezes apontando, nestes gêneros, o uso da norma culta e ou uma infração quanto a ela.

Passemos agora a atender ao novo modelo de gramática que temos observado nesses últimos anos. Destacamos, dentre essas novas gramáticas, a "Pequena Gramática do Português Brasileiro" (PGPB) de Ataliba T. de Castilho e Vanda Maria Elias (2012). A escolha se deu, primeiro porque se trata de uma gramática de cunho didático, conforme destaca o autor e, segundo, porque é um exemplar explícito do que chamamos "gramáticas dos linguístas".

Em um breve resumo do currículo dos autores, encontramos: Ataliba T. de Castilho é professor titular da Universidade de São Paulo e dirigiu projetos como o 
Nurc e o Gramática do Português Falado. Pesquisador de pós-doutorado. Presidiu, de 1983, a Associação Brasileira de Linguística, Vanda Maria Elias é doutora em Língua Portuguesa pela PUC- SP, membro do GT Linguística do Texto e Análise da Conversação, da Associação Nacional de Pesquisa em Letras e Linguística (ANPOLL). Ao atentar para os dados dos autores, já consideramos dados que são diferenciados da autoria da gramática analisada. Cegalla é considerado um gramático em essência e não seguiu carreira como professor universitário, nem despontou em meios científicos. Já os autores da nova gramática são linguístas por formação. Suas formações parecem favorecer novas abordagens nas questões linguísticas, como notamos na análise comparativa.

Há, portanto, aqui algo diferenciado e já notado por estudiosos, este exemplo de gramática (e todos as gramáticas de linguísticas) estão "demarcando uma forma de entrada dos linguistas no jogo de des/legitimação que constitui para os brasileiros sua identidade linguística" (FARIAS, 2014, p. 120).

Em sua apresentação, dedica o volume "aos professores de Língua Portuguesa interessados na variedade brasileira, aos alunos de Letras e Pedagogia, aos alunos do ensino médio e a todos os brasileiros que queiram refletir sobre a língua que falamos "(CASTILHO; ELIAS, 2012, p.14). Observamos que os autores, de início, destacam duas questões novas na gramática: a variedade que estarão contemplando - brasileira - e o fato de buscarem leitores que queiram "refletir" sobre a língua.

Os autores enfatizam que a gramática PGPB não se apresenta como uma gramática tradicional cuja função é mostrar uma "língua engessada" (p.14). Diferente do gênero gramática analisado, a PGPB se apresenta com um objetivo maior entre seus falantes: "provocar a indagação, desenvolver o espírito crítico que se espera de cidadãos de uma democracia" (p. 14).

Além disso, a temática do gênero discursivo, portanto, é delineada como fatos linguísticos, como a gramática do Cegalla, porém do "português brasileiro". Destacamos que os autores mencionam o ensino da norma culta, porém de modo diferenciado, reflexivo e não normativo, atendendo para outra variante linguística além da padrão:

É evidente que podemos e devemos ensinar a modalidade escrita, e também como se deve manejar o idioma em sua modalidade culta, padrão. Essa é a língua do Estado, de que devemos nos apropriar, pois ela promove socialmente seus usuários. Não deixamos isso de lado, pelo contrário: estamos convencidos de que a reflexão sobre a língua abre um caminho de maior eficiência nessa direção. Ao mesmo tempo que expressamos nosso conhecimento sobre o português brasileiro, reconhecemo-nos como falantes do português brasileiro. (CASTILHOS; ELIAS, 2012, p. 14)

Outra, digamos, novidade nessa gramática é o conteúdo, não aparece padronizado, observando o sumário, verificamos, juntamente com antigos 
conteúdos, novas categorias sendo apresentadas. Conforme a resenha de Gomes de Matos (UFPE, 2010), temos a seguinte divisão: 1. 0 que se entende por língua (30p.); 2. Estrutura fonológica e morfológica da palavra (34 p); 3. 0 pronome (48 p.); 4 . 0 verbo (64 p.); 5.0 artigo, o substantivo e o adjetivo (52 p.); 6.0 advérbio (34 p.); 7. A preposição (34 p.); 8.Mini sentença, sentença simples, sentença complexa (80 p.); 9 . 0 texto (44 p.); 10 . História e diversidade do Português Brasileiro (30 p).

Olhando para o índice, o leitor já contempla a proposta diferenciada de Castilho e Elias (2012) que busca "desenvolver o raciocínio científico em nossos alunos, arrastando-os para o prazer da descoberta” (p. 15). Sem dúvida, isso não é comum em gramáticas normativas, que trazem tudo como fato inquestionável, sendo assim que os conteúdos são repassados aos alunos (maior parte das vezes), os quais acabam por entender a gramática como disciplina de regras absolutas e não como um lugar de reflexão. Também esses estudos com classes gramáticas em conjunto, destacadas na PGPB, enfatizando suas relações e semelhanças na língua são maneiras diferenciadas de pensar o estudo da língua. Ressaltamos que, além disso, ao proporem as divisões do estudo avisam que a ordem dos estudos dos capítulos pode ser flexível, não sendo necessário seguir uma sequência rígida, como quase sempre a gramática normativa.

Uma outra mudança interessante que percebemos nesse exemplar de gramática dos linguístas diz respeito ao estilo. É uma gramática interativa, os autores, ao exporem as teorias, conversam com seus leitores criando um ambiente de interação em linguagem simples e próxima das falas do cotidiano

Você decerto já ouvir dizer que a língua portuguesa é muito difícil. Mas será mesmo? O que seria uma língua difícil? (...)

Vamos testar isso. Você vai andando pela rua e escuta esta conversa entre dois estudantes do ensino médio (...) (ob. cit. P. 17) (...)

Moral da história: a transitividade é uma propriedade da sentença, não do verbo. (p. 139)

Durante todo o texto, os autores interagem com seus leitores, procurando explicar e parecem favorecer uma abordagem dos usos linguísticos mais próxima do português brasileiro usado no cotidiano do brasileiro.

A finalidade do gênero não é, dessa forma, normatizar, preescrever regras, porém bem explicitada, "fazer ciência":

Trocamos as chatices do dia a dia pelo prazer do desafio e da descoberta, estabelecendo com professores e alunos um diálogo continuado, em que perguntas são formuladas, respostas são 
buscadas, as quais inevitavelmente nos levarão a novas perguntas, pois é assim que se faz ciência.

(...) procuramos desenvolver o raciocínio científico em nossos alunos, arrastando-os para o prazer da descoberta. (p. 15)

A partir dessa finalidade do gênero, observamos que, se pudéssemos classificar a gramática de Castilho e Elias, não se encaixaria na normativa apresentada por Possenti (1997) e Travaglia (1998). Mas seria uma gramática descritiva? Ainda temos dúvida, uma vez que observamos que os autores não somente descrevem uma variante linguística sincronicamente, como seria comum à gramática descritiva, porém, aos apresentarem os estudos da língua, assumem posições contrárias quanto à gramática normativa. Não se apresentam neutros, mas reforçam estarem procurando outro lugar de estudo do uso do português brasileiro. Não deixam, ainda, de apresentar as regras e destacam os usos da norma culta, porém em tom menos normativo que a gramática de Cegalla (1978), possibilitando que o leitor observe que há outras formas de uso e que a padrão tem suas características também. Por exemplo:

(a) 0 aumento desses crimes está provocando situações irreversíveis. (português padrão)

(b) 0 aumento desses crimes estão provocando situações irreversíveis. (português não padrão)

O português padrão não aceita a concordância observada em (b)

(CASTILHO; ELIAS, 2012, p. 149)

Em suma, a PGPB se mostra como uma gramática diferenciada propondo novidades quanto ao discurso pedagógico do gênero gramática na escola.

\section{CONCLUSÃO}

Refletir sobre o papel da gramática na sociedade é sempre algo a ser feito uma vez que esse gênero ocupa lugar de supremacia nos estudos da língua. Por isso, nosso trabalho objetivou pensar a gramática enquanto gênero ou suporte de texto. E para início de discussão, acreditamos que é possível pensar a gramática enquanto gênero discursivo presente nas salas de aulas. Em função de várias questões que apontamos, dentre elas o fato de a gramática ser um gênero marcado pelo plurilinguísmo.

Também nos propomos a olhar para um exemplo de nova gramática que tem aparecido nos últimos anos e procurar pensá-la em comparação com o gênero gramática tradicional que conhecemos há longa data. 0 que entendemos é que a PGPB é um novo tipo de gramática que - ainda não se sabe - pode ser pensada como descritiva, porém com alterações. 0 fato é que os lingüistas estão assumindo um lugar que era ocupado apenas por gramáticos e reclamam, sem dúvida, um 
novo olhar para a(s) língua(s) do Estado.

Em PGPB, há uma tentativa de criar alunos críticos, estudiosos da língua pensantes que vejam a língua, a gramática como um lugar de fazer ciência e não como matéria dada e regra a ser seguida. Acreditamos ser um vislumbre de novas políticas linguísticas no Brasil, de lugares de menor discriminação e maior valorização do português brasileiro, resta saber se essa nova roupagem do gênero gramática vai resistir à tradição da gramática normativa do tradicional Cegalla (1978)

\section{Notas}

${ }^{1}$ Doutoranda em Letras ; Universidade Federal do Paraná.

profmaisa2009@hotmail.com

Referências

BAKHTIN, Mikhail. M; VOLOCHINOV, Valentin. N. Estética da criação verbal. São Paulo: M. Fontes, 2004.

CASTILHO, Ataliba T. de e Vanda Maria ElIAS. 2012. Pequena Gramática do Português Brasileiro. São Paulo: Contexto.

CASTILHO, Ataliba T. de. 2010. Nova Gramática do Português Brasileiro. São Paulo: Editora Contexto. Resenha de Gomes de Matos, F.: D.E.L.T.A., 26:1, 2010 (205-211) CEGALlA, Domingos P. Novíssima Gramática da Língua Portuguesa. 18. ed. São Paulo: Nacional, 1978.

DOLZ, Joaquim.; SCHNEUWLY, Bernard. Gêneros e progressão em expressão oral e escrita - Elementos para reflexões sobre uma experiência suíça (francófona). In: ROJO, Roxane.; CORDEIRO, Glaís. Sales. (Org.). Gêneros orais e escritos na escola. Campinas, SP: Mercado de Letras, 2004. p. 41-70

FARIAS, Washington Silva de. As gramáticas dos linguístas no Brasil: efeitos de sentido polêmicos sobre a língua a re-conhecer. Linguagem em (Dis)curso - LemD, Tubarão, SC, v. 14, n. 1, p. 105-122, jan./abr. 2014.

MARCUSCHI, Luiz Antônio. Gêneros textuais: definição e funcionalidade. In: DIONIOSIO, Angela Paiva; MACHADO; Anne Rachel; BEZERRA; Maria. Auxiliadora. (Org.). Gêneros textuais e ensino. 2. ed. Rio de Janeiro: Lucerna, 2002. p. 19-36.

MARCUSCHI, Luiz Antônio. A questão do suporte dos gêneros textuais. Recife:2003 $<$

http://www.sme.pmmc.com.br/arquivos/matrizes/matrizes portugues/anexos/t exto-15.pdf $>$ Acesso em 9 de janeiro de 2016. 
POSSENTI, Sírio. Por que (não) ensinar gramática na escola. Campinas, ALB.' Mercado de Letras, 1997, 96 p., Coleção Leituras do Brasil.

SCHNEUWLY, Bernard. Gêneros e tipos de discurso: considerações psicológicas e ontologéticas. In: ROJO, Roxane; CORDEIRO, GLaís . S. (Org.). Gêneros orais e escritos na escola. Campinas, SP: Mercado de Letras, 2004. p. 21-39.

SOARES, Magda. Português na escola - História de uma disciplina curricular. In: BAGNO, Marcos (Org.). Linguística da norma. São Paulo: Loyola, 2002.

TRAVAGLIA, Luiz Carlos. Gramática e interação: uma proposta para o ensino de gramática no $1^{\circ}$ e $2^{\circ}$ graus. 2.ed. São Paulo: Cortez, 1998.

\section{Para citar este artigo}

CARDOSO, Maísa. GRAMÁTICA: GÊNERO DISCURSIVO EM MUTAÇÃO?. Macabéa - Revista Eletrônica do Netlli, Crato, v. 6, n. 2, p. 39-53, jul.-dez. 2017.

\section{Os autores}

Maísa Cardoso possui graduação em Letras - Português pela Universidade Estadual de Maringá (2001) e mestrado em Letras pela Universidade Estadual de Maringá (2009). Tem experiência na área de Estudos linguísticos atuando principalmente nos seguintes temas: formação de professores, gêneros textuais, gêneros discursivos, letramentos, linguística aplicada, ideologia linguística, interculturalidade. É doutoranda na Universidade Federal do Paraná. 